Supporting Information for

\title{
Cross-Linked Small-Molecule Micelle-Based Drug Delivery System: Concept, Synthesis, and Biological Evaluation
}

\author{
Chunyan Liao, ${ }^{\dagger, *}$ Yun Chen, ${ }^{*}$ Yongchao Yao, ${ }^{*}$ Shiyong Zhang, ${ }^{*}{ }^{\dagger, *}$ Zhongwei Gu, ${ }^{\ddagger}$ and Xiaoqi Yu \\ ${ }^{\dagger}$ College of Chemistry, Sichuan University, 29 Wangjiang Road, Chengdu 610064, China \\ $¥$ National Engineering Research Center for Biomaterials, Sichuan University, 29 Wangjiang Road, \\ Chengdu 610064, China
}




\section{General Methods}

Routine NMR spectra were obtained on a Bruker AV II-400. The ${ }^{1} \mathrm{H}$ NMR chemical shifts were measured relative to $\mathrm{CD}_{3} \mathrm{OD}$ or DMSO- $d_{6}$ as the internal reference $\left(\mathrm{CD}_{3} \mathrm{OD}: \delta 3.31 \mathrm{ppm}\right.$; DMSO- $d_{6}: \delta$ $2.50 \mathrm{ppm})$. The ${ }^{13} \mathrm{C}$ NMR chemical shifts were given using $\mathrm{CD}_{3} \mathrm{OD}$ or DMSO- $d_{6}$ as the internal standard ( $\mathrm{CD}_{3} \mathrm{OD}: \delta 49.00 \mathrm{ppm}$; DMSO- $\left.d_{6}: \delta 39.52 \mathrm{ppm}\right)$. Mass spectrometry was performed on a Waters Q-Tof premier instrument. Gel permeation chromatography (GPC) was performed on a Waters1515 instrument using tetrahydrofuran (THF) as the mobile phase at a flow rate of $1 \mathrm{~mL} \mathrm{~min}^{-1}$ at $40{ }^{\circ} \mathrm{C}$ and the molecular weights were reported relative to polystyrene (PS) standards. The fluorescence emission intensity of Nile red at the wavelength of $525 \mathrm{~nm}$ (excited at $485 \mathrm{~nm}$ ) was measured using a Hitachi F-7000 fluorescence spectrometer. The particle size and zeta potential were measured with a Dynamic Light Scattering (DLS) Analyzer (Malvern ZetasizerNano ZS90). TEM studies were carried out using a TecnaiG2F20S-TWIN instrument, operating at $120 \mathrm{kV}$. The TEM specimens were prepared by gently placing a carbon-coated copper grid on the surface of the sample. The TEM grid was then removed, stained with an aqueous solution of $2 \%$ phosphotungstic acid, dried for $0.5 \mathrm{~h}$ at room temperature, and then subjected to TEM observation. The in vitro release of gemcitabine was performed in sink (AHYQ SHA-C) at $37{ }^{\circ} \mathrm{C}$. The gemcitabine standard curve and the in vitro release of gemcitabine were analyzed at $268 \mathrm{~nm}$ by HPLC (Agilent $1260 \mathrm{LC}$, Zorbax C18 column $4.6 \times 150 \mathrm{~mm}$ ) with gradient elution from 2 to $90 \%$ of Buffer B within 20 min and flow rate $1.0 \mathrm{~mL} / \mathrm{min}$ (Buffer A: deionized water with $0.1 \%$ trifluoroacetic acid (TFA), Buffer B: acetonitrile containing 0.1\% TFA). Human nonsmall-cell lung cancer (A549) was obtained from Chinese Academy of Science Cell Bank for Type Culture Collection (Shanghai, China) and used for all of cell experiments and animal experiments. The cell line was grown in Roswell Park Memorial Institute (RPMI-1640) supplemented 
with $10 \%(\mathrm{v} / \mathrm{v})$ fetal bovine serum (FBS) and $1 \%(\mathrm{v} / \mathrm{v})$ penicillin/streptomycin in an incubator under $5 \%$ $\mathrm{CO}_{2}$ at $37{ }^{\circ} \mathrm{C}$. Cell toxicity was evaluated by measuring the percentage of cell viability via the Cell Counting Kit-8 assay (CCK-8). The absorbance at $450 \mathrm{~nm}$ was then measured using a microplate reader Varioscan Flash (ThermoFisher SCIENTIFIC). The cell viability (\%) was obtained according to the manufacturer's instructions. The cellular uptake of A549 cells incubated with DiI-loaded micelles (DiI: 1,1'-dioctadecyl-3,3,3',3'-tetramethylindo-carbocyanine) was observed under confocal laser scanning microscopy (CLSM, Leica TCP SP5) and measured by flow cytometry (BectoDickinson, USA). Cellassociated DiI was excited with an argon laser $(549 \mathrm{~nm})$ and the emitted fluorescence was detected at $565 \mathrm{~nm}$. The animals were purchased from Institute of Laboratory Animals of Sichuan Academy of Medical Sciences \& Sichuan Provincial People's Hospital.

Chemicals: Unless otherwise noted, all reagents were obtained from commercial suppliers and used without further purification. All solvents for reactions were freshly distilled prior to use. Deionized water was used in all aqueous experiments.

\section{Synthesis}

Scheme 1S. Synthesis of compound 1

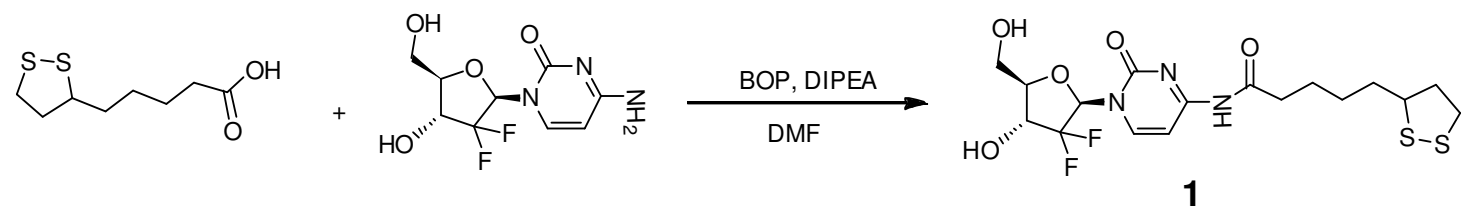

Compound 1. ${ }^{1}$ Gemcitabine $\cdot \mathrm{HCl}(50 \mathrm{mg}, 0.17 \mathrm{mmol})$ and diisopropyl ethyl amine (DIPEA, $33 \mu \mathrm{L}$, $0.2 \mathrm{mmol}$ ) were dissolved in $1 \mathrm{~mL}$ of dry $N, N$-dimethylformamide (DMF). (Benzotriazol-1-yloxy) tris(dimethylamino) phosphonium hexafluophosphate (BOP, $89 \mathrm{mg}, 0.2 \mathrm{mmol}$ ) and lipoic acid (42 $\mathrm{mg}, 0.2$ mmol) were dissolved in $2 \mathrm{~mL}$ dry DMF were added dropwise. The solution was stirred under $\mathrm{N}_{2}$ for 24 
$\mathrm{h}$, then water $(4 \mathrm{~mL})$ and $10 \% \mathrm{HCl}(1 \mathrm{~mL})$ were added, and the mixture was extracted with ethyl acetate

$(3 \times 15 \mathrm{~mL})$. The organic phase was washed with saturated $\mathrm{NaHCO}_{3}$ and brine, dried over anhydrous $\mathrm{MgSO}_{4}$. The solvent was removed under vacuum and the residue was purified by column chromatography $\left(\mathrm{CH}_{2} \mathrm{Cl}_{2}: \mathrm{MeOH}\right.$ from $60: 1$ to $\left.40: 1\right)$ to give 1 as a yellow oil (50 mg, 65\%). ${ }^{1} \mathrm{H}$ NMR (400 MHz, CD 3 OD): $8.35(\mathrm{~d}, J=7.6 \mathrm{~Hz}, 1 \mathrm{H}), 7.50(\mathrm{~d}, J=7.6 \mathrm{~Hz}, 1 \mathrm{H}), 6.26(\mathrm{t}, J=7.2 \mathrm{~Hz}, 1 \mathrm{H}), 4.35-$ $4.27(\mathrm{~m}, 1 \mathrm{H}), 4.00-3.96(\mathrm{~m}, 2 \mathrm{H}), 3.83-3.80(\mathrm{~m}, 1 \mathrm{H}), 3.61-3.55(\mathrm{~m}, 1 \mathrm{H}), 3.20-3.07(\mathrm{~m}, 2 \mathrm{H}), 2.51-2.44(\mathrm{~m}$, $3 \mathrm{H}), 1.94-1.86(\mathrm{~m}, 1 \mathrm{H}), 1.76-1.64(\mathrm{~m}, 4 \mathrm{H}), 1.55-1.45(\mathrm{~m}, 2 \mathrm{H}) .{ }^{13} \mathrm{C}$ NMR (100 MHz, CD $\left.{ }_{3} \mathrm{OD}\right): 175.70$, $164.79,157.66,145.93,98.26,82.76,70.11,60.22,57.46,41.28,39.35,37.89,36.99,35.76,29.76$, 25.63. High resolution ESI-MS: $[\mathrm{M}+\mathrm{Na}]^{+}$calcd for $\mathrm{C}_{17} \mathrm{H}_{23} \mathrm{~F}_{2} \mathrm{~N}_{3} \mathrm{NaO}_{5} \mathrm{~S}_{2}{ }^{+}$474.0945, found 474.0894.

Scheme 2S. Synthesis of compound 2

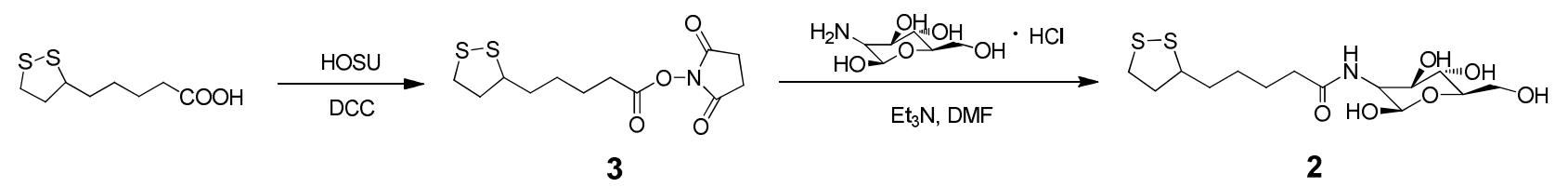

Compound 3. ${ }^{2}$ Lipoic acid (200 mg, $0.97 \mathrm{mmol}$ ), $N$-hydroxysuccinimide (HOSU, $138 \mathrm{mg}, 1.2$ mmol), and 1,3-dicyclohexylcarbodiimide (DCC, $247 \mathrm{mg}, 1.2 \mathrm{mmol}$ ) were dissolved in $7 \mathrm{~mL}$ of tetrahydrofuran (THF). The mixture was stirred under nitrogen atmosphere at room temperature for $6 \mathrm{~h}$. The precipitate was removed by filtration, and the filtrate was concentrated under reduced pressure to give 3 a light yellow powder (270 mg, 92\%), which was used for the next step without any further purification.

Compound 2. ${ }^{3}$ Compound $3(270 \mathrm{mg}, 0.89 \mathrm{mmol})$ and 2-amino-2-deoxy-D-glucose hydrochloride $(383.0 \mathrm{mg}, 1.78 \mathrm{mmol})$ were dissolved in $8 \mathrm{~mL}$ dry DMF in the presence of triethylamine $(0.25 \mathrm{~mL}$, $1.78 \mathrm{mmol}$ ) under nitrogen protection. The mixture was stirred at room temperature for $48 \mathrm{~h}$. DMF was removed under vacuum and the residue was purified by the column chromatography with $\mathrm{CH}_{2} \mathrm{Cl}_{2^{-}}$ 
$\mathrm{MeOH}(10: 1)$ to give 2 as a light yellow powder $(278 \mathrm{mg}, 85 \%) .{ }^{1} \mathrm{H}$ NMR $\left(400 \mathrm{MHz}\right.$, DMSO- $\left.d_{6}\right): 7.53$

$(\mathrm{d}, J=8.08 \mathrm{~Hz}, 1 \mathrm{H}), 6.39(\mathrm{~d}, J=4.24 \mathrm{~Hz}, 1 \mathrm{H}), 4.91(\mathrm{~s}, 1 \mathrm{H}), 4.88(\mathrm{~d}, J=5.4 \mathrm{~Hz}, 1 \mathrm{H}), 4.57(\mathrm{~d}, J=5.52$,

$1 \mathrm{H}), 4.45-4.40(\mathrm{~m}, 1 \mathrm{H}), 3.63-3.56(\mathrm{~m}, 3 \mathrm{H}), 3.51-3.44(\mathrm{~m}, 2 \mathrm{H}), 3.22-3.15(\mathrm{~m}, 1 \mathrm{H}), 3.13-3.08(\mathrm{~m}, 1 \mathrm{H})$,

2.45-2.37 (m, 1H) 2.13-2.06 (m, 2H), 1.89-1.84 (m, 1H), 1.70-1.63 (m, 1H), 1.58-1.46 (m, 3H), 1.39-

$1.33(\mathrm{~m}, 2 \mathrm{H}) .{ }^{13} \mathrm{C}$ NMR (100 MHz, DMSO-d $): 172.62,91.08,72.53,71.63,71.34,70.92,61.59,56.61$, 54.66, 38.56, 35.51, 34.62, 28.81, 25.53. High resolution ESI-MS : $[\mathrm{M}+\mathrm{Na}]^{+}$calcd for $\mathrm{C}_{14} \mathrm{H}_{25} \mathrm{NNaO}_{6} \mathrm{~S}_{2}{ }^{+}$390.1021, found 390.0985.

Typical preparation of small-molecule micelles. Compound $\mathbf{1}(25 \mu \mathrm{L}, 0.1 \mathrm{mmol} / \mathrm{mL}$ in dimethyl sulphoxide) was added dropwise into $5.0 \mathrm{~mL}$ of deionized water under vortex at room temperature. The resulting solution was then left to stand and the micelles formed spontaneously within minutes. as a pale blue emulsion.

Determination of the critical micelle concentration(CMC) of amphiphile $1{ }^{4}$ A known amount of nile red in $\mathrm{CH}_{2} \mathrm{Cl}_{2}$ was added to a series of vials and the $\mathrm{CH}_{2} \mathrm{Cl}_{2}$ was evaporated. The amount was chosen to give a nile red concentration of $1 \times 10^{-6} \mathrm{M}$ in the final solution. A measured amount of $\mathbf{1}$ solution was added to each vial and the deionized water was added to the vials to make the concentrations of amphiphile 1 ranging from 2 to $1024 \mu \mathrm{M}$. The vials were vibrated at room temperature overnight, and then the fluorescence emission intensity at the wavelengths of $525 \mathrm{~nm}$ (excited at $485 \mathrm{~nm}$ ) was measured. The critical micelle concentration was obtained as the intersection of the tangents to the two linear portions of the graph of the fluorescence intensity as a function of [1]. From Figure 1S, the CMC of amphiphile 1 was $\sim 55 \mu \mathrm{M}$.

Typical preparation of cross-linked small-molecule micelle based drug delivery system (CSM-DDS). The CSM-DDS was prepared under nitrogen atmosphere at room temperature in the 
presence of $10 \mathrm{~mol} \%$ dithiothreitol (DTT) relative to the lipoyl units. ${ }^{5}$ Briefly, $5.0 \mathrm{~mL}$ of micelle dispersion $([\mathbf{1}]=0.5 \mathrm{mM})$ was added DTT $(39 \mu \mathrm{g}, 10 \mathrm{~mol} \%$ relative to the lipoyl units $)$ solution in deionized water $(0.1 \mathrm{~mL})$. The mixture was stirred at room temperature for 1 day and dialyzed against deionized water for another day (Spectra/Pore, MWCO 1000) to get the CSM-DDS as a pale blue solution.

For the preparation of targeted CSM-DDS, the same procedure was employed except replacement of the micelle dispersion with the amphiphile 2 contained micelle solution $([\mathbf{1}]=0.5 \mathrm{mM} ;[\mathbf{2}]=0.05$ $\mathrm{mM}$ ).

In vitro stability assay. The dilution stability of cross-linked small-molecule micelle was evaluated by diluting the concentrations of $\mathbf{1}$ below its CMC $(55.0 \mu \mathrm{M})$. Briefly, the cross-linked micelles $([\mathbf{1}]=500.0 \mu \mathrm{M})$ was diluted to the concentrations of $250.0 \mu \mathrm{M}, 125.0 \mu \mathrm{M}, 62.5 \mu \mathrm{M}, 32.0 \mu \mathrm{M}$, $16.0 \mu \mathrm{M}, 8.0 \mu \mathrm{M}$, respectively. Afterwards, the particle sizes of above solutions were recorded by DLS to evaluate its stability.

The FBS stability of small-molecule micelles and cross-linked small-molecule micelles was investigated by incubation with $10 \%$ (V/V) FBS. Briefly, $9 \mathrm{~mL}$ of small-molecule micelles and crosslinked small-molecule micelles $([\mathbf{1}]=0.5 \mathrm{mM}$, in deionized water) were mixed with $1 \mathrm{~mL}$ FBS, respectively. The particle sizes at $0 \mathrm{~h}$ and after $1 \mathrm{~h}$ of incubation at $37^{\circ} \mathrm{C}$ were recorded to evaluate their stability.

In vitro release assay. The release of cross-linked small-molecule micelle was studied in the presence and absence of Cathepsin B $(5 \mathrm{U} / \mathrm{mL}){ }^{6}$ Briefly, the solutions of small-molecule micelle and cross-linked small-molecule micelle (equivalent to $0.5 \mathrm{mM}$ of gemcitabine) formulated in phosphate buffer saline (PBS, $10 \mathrm{~mL}, \mathrm{PH} 5.5,20 \mathrm{mM}$ ) with or without $40 \mu \mathrm{L}$ Cathepsin B were put into the sink at 
$37{ }^{\circ} \mathrm{C}$. At predetermined time points, a $500 \mu \mathrm{L}$ sample was collected and test immediately. The content of gemcitabine presented in the samples was determined by high performance liquid chromatography (HPLC).

Cellular uptake evaluation by confocal laser scanning microscopy (CLSM). A549 cells $\left(5 \times 10^{4}\right.$ cells $/ \mathrm{mL}$ ) were seeded in a $\Phi=35 \mathrm{~mm}$ glass Petri dish and incubated at $37{ }^{\circ} \mathrm{C} / 5 \% \mathrm{CO}_{2}$ for $24 \mathrm{~h}$. Subsequently, the cells were cultured with equal concentration of DiI loaded non-targeted CSM-DDS and targeted CSM-DDS $\left([1]=0.5 \mathrm{mM},[\mathrm{DiI}]=5 \mu \mathrm{g} / \mathrm{mL}, \lambda_{\mathrm{Ex}}=549 \mathrm{~nm}, \lambda_{\mathrm{Em}}=565 \mathrm{~nm}\right)$, at $37^{\circ} \mathrm{C}$ for $1 \mathrm{~h}$, $3 \mathrm{~h}, 7 \mathrm{~h}$ and $16 \mathrm{~h}$, respectively. The culture medium was removed and the cells were washed three times with PBS. Then the nuclei were stained by blue molecular probe (Hoechst $33342, \lambda_{\mathrm{Ex}}=350 \mathrm{~nm}, \lambda_{\mathrm{Em}}=$ $460 \mathrm{~nm}$ ) for $15 \mathrm{~min}$. The medium was removed and washed three times with PBS and another $1 \mathrm{~mL}$ PBS was added. The cellular uptake was observed under CLSM.

Cellular uptake study by flow cytometry. A549 cells $\left(2 \times 10^{4}\right.$ cells/mL $)$ were seeded in 6 -well culture plates and allowed to incubate at $37^{\circ} \mathrm{C} / 5 \% \mathrm{CO}_{2}$ for $36 \mathrm{~h}$. Subsequently, the culture medium was replaced by $2 \mathrm{~mL}$ of fresh medium containing equal concentration of DiI-loaded non-targeted CSMDDS or targeted CSM-DDS $([\mathbf{1}]=0.5 \mathrm{mM})$ while untreated cells were set as control. After incubation at $37^{\circ} \mathrm{C}$ for $6 \mathrm{~h}$, the culture medium was removed, and the cells were washed with PBS for three times and digested with trypsin. Afterwards, culture medium $(1 \mathrm{~mL})$ was added to each well, and the solutions were centrifuged for $5 \mathrm{~min}$ at $1200 \mathrm{rpm}$. After removal of the supernatants, the cell pellets were resuspended in $500 \mu \mathrm{L}$ of PBS. The fluorescence signal was analyzed by flow cytometry.

Cytotoxicity assay. In vitro cytotoxicity was assessed by the Cell Counting Kit-8 assay (CCK-8). Briefly, A549 cells (5000/well) were seeded in 96-well culture plates and incubated at $37{ }^{\circ} \mathrm{C} / 5 \% \mathrm{CO}_{2}$. After $24 \mathrm{~h}$, culture media was removed and fresh media $(200 \mu \mathrm{L})$ containing free gemcitabine, uncross- 
linked small-molecule micelles, CSM-DDS, and targeted CSM-DDS at various gemcitabine concentration which ranging from $0.003 \mu \mathrm{g} / \mathrm{mL}$ to $300 \mu \mathrm{g} / \mathrm{mL}$ were added to each well, separately. Cells without any treatment were set as control. After 72 h, culture media was removed and fresh media (100 $\mu \mathrm{L})$ containing CCK-8 $(10 \mu \mathrm{L})$ was added to each well and the plates were incubated at $37{ }^{\circ} \mathrm{C}$ for another $2 \mathrm{~h}$. Then, the absorbance at $450 \mathrm{~nm}$ of each sample was measured using a microplate reader Varioscan Flash. To assess the toxicity of the blank material, the cytotoxicity of cross-linked nanoparticles formed by lipoic acid only was also assessed using the same protocol in the concentration range from $0.002 \mu \mathrm{g} / \mathrm{mL}$ to $200 \mu \mathrm{g} / \mathrm{mL}$.

Biodistribution study. The tissue distribution studies of CSM-DDS and targeted CSM-DDS were performed in all mice at $2.0 \mathrm{~h}$ postinjection. When the tumor volumes reached $100-300 \mathrm{~mm}^{3}$, the mice were randomized into two treatment groups (5 mice per group). Each group was intravenously administrated with $20.0 \mathrm{mg} / \mathrm{kg}$ gemcitabine equivalent dose of CSM-DDS or targeted CSM-DDS. To assess gemcitabine concentration in different tissues, normal organs (heart, liver, spleen, lung, and kidney) and tumor tissues were harvested after $2 \mathrm{~h}$. Tissue homogenate samples were treated with glacial acetic acid to terminate possible deamination and were precipitated with acetonitrile. Following the centrifugation at $12000 \mathrm{rpm}$ for $5 \mathrm{~min}$, the supernatants were evaporated overnight. The dried samples were reconstituted in the mobile phase, and the contents of gemcitabine presented in the samples were determined by high performance liquid chromatography (HPLC).

In vivo antitumor evaluation. In vivo antitumor efficacy was investigated in subcutaneous A549 xenograft model. To produce tumors, 4 weeks old male nude mice were inoculated subcutaneously with $1 \times 10^{6}$ A549 cells suspended in $100 \mu \mathrm{L}$ PBS. Solid tumors were allowed to form over 2-3 weeks to reach a volume about $100 \mathrm{~mm}^{3}$. The mice bearing tumors were randomly divided into 5 groups $(\mathrm{n}=5)$ and 
treated with $100 \mu \mathrm{L}$ saline (control), free gemcitabine (5 $\mathrm{mg} \mathrm{kg}^{-1}$ ), uncross-linked small-molecule micelles (5 mg kg-1 Gem-equivalent dose), CSM-DDS (5 $\mathrm{mg} \mathrm{kg}^{-1}$ Gem-equivalent dose) or targeted CSM-DDS (5 $\mathrm{mg} \mathrm{kg}^{-1}$ Gem-equivalent dose) via tail-vein injection every three days for three weeks. To determine the treatment efficacy, the animals were monitored routinely for tumor growth and bodyweight change. The day that mice received materials was set as day 0 , and the tumor volume and body weight at day 0 was normalized to $100 \%$. All subsequent tumor volumes and body weight were expressed as the percentage relative to those at day 0 . The tumor volumes were calculated through the following formula: tumor volume $\mathrm{V}\left(\mathrm{mm}^{3}\right)=1 / 2 \times$ length $(\mathrm{mm}) \times$ width $^{2}(\mathrm{~mm})$. On the 21 th day, all animals were sacrificed. 


\section{References}

1. Harrisson, S.; Nicolas, J.; Maksimenko, A.; Bui, D.; Mougin, J.; Couvreur, P. Nanoparticles with in vivo anticancer activity from polymer prodrug amphiphiles prepared by living radical polymerization. Angew. Chem. Int. Ed. 2013, 52, 1678-1682.

2. Zhang, S.; Zhao, Y. Controlled release from cleavable polymerized liposomes upon redox and $\mathrm{pH}$ stimulation. Bioconjugate Chem. 2011, 22, 523-528.

3. Dufes, C.; Schätzlein, A.; Tetley, L.; Gray, A.; Watson, D.; Olivier, J.; Couet, W.; Uchegbu, I. Niosomes and polymeric chitosan based vesicles bearing transferrin and glucose ligands for drug targeting. Pharm. Res. 2000, 17, 1250-1258.

4. Shen, Y.; Jin, E.; Zhang, B.; Murphy, C.; Sui, M.; Zhao, J.; Wang, J.; Tang, J.; Fan, M.; Kirk, E.; Murdoch, W. Prodrugs Forming high drug-loading multifunctional nanocapsules for cancer intracellular drug delivery. J. Am. Chem. Soc. 2010, 132, 4259-4265.

5. Wei, R.; Cheng, L.; Zheng, M.; Cheng, R.; Meng, F.; Deng, C.; Zhong, Z. Reduction-responsive disassemblable core-cross-linked micelles based on poly(ethylene glycol)-b-poly(N-2hydroxypropyl methacrylamide)-lipoic acid conjugates for triggered intracellular anticancer drug release. Biomacromolecules. 2012, 13, 2429-2438.

6. Chitkara, D.; Mittal, A.; Behrman, S.; Kumar, N.; Mahato, R. Self-assembling, amphiphilic polymer-gemcitabine conjugate shows enhanced antitumor efficacy against human pancreatic adenocarcinoma. Bioconjugate Chem. 2013, 24, 1161-1173. 


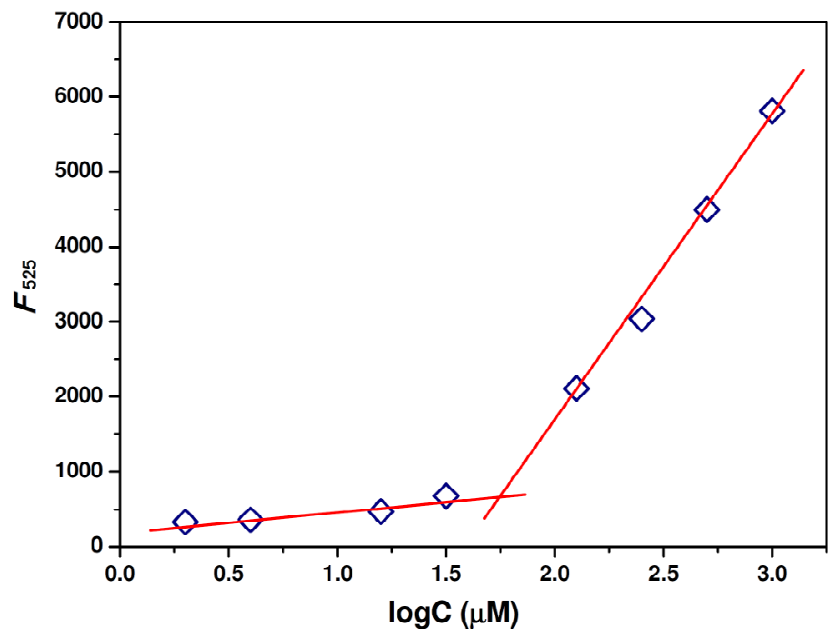

Figure 1S. Emission intensity at $525 \mathrm{~nm}\left(F_{525}\right)$ of nile red as a function of concentrations of 1 in water. [nile red] $=1.0 \times 10^{-6} \mathrm{~mol} / \mathrm{L}, \lambda_{\mathrm{ex}}=485 \mathrm{~nm}$.

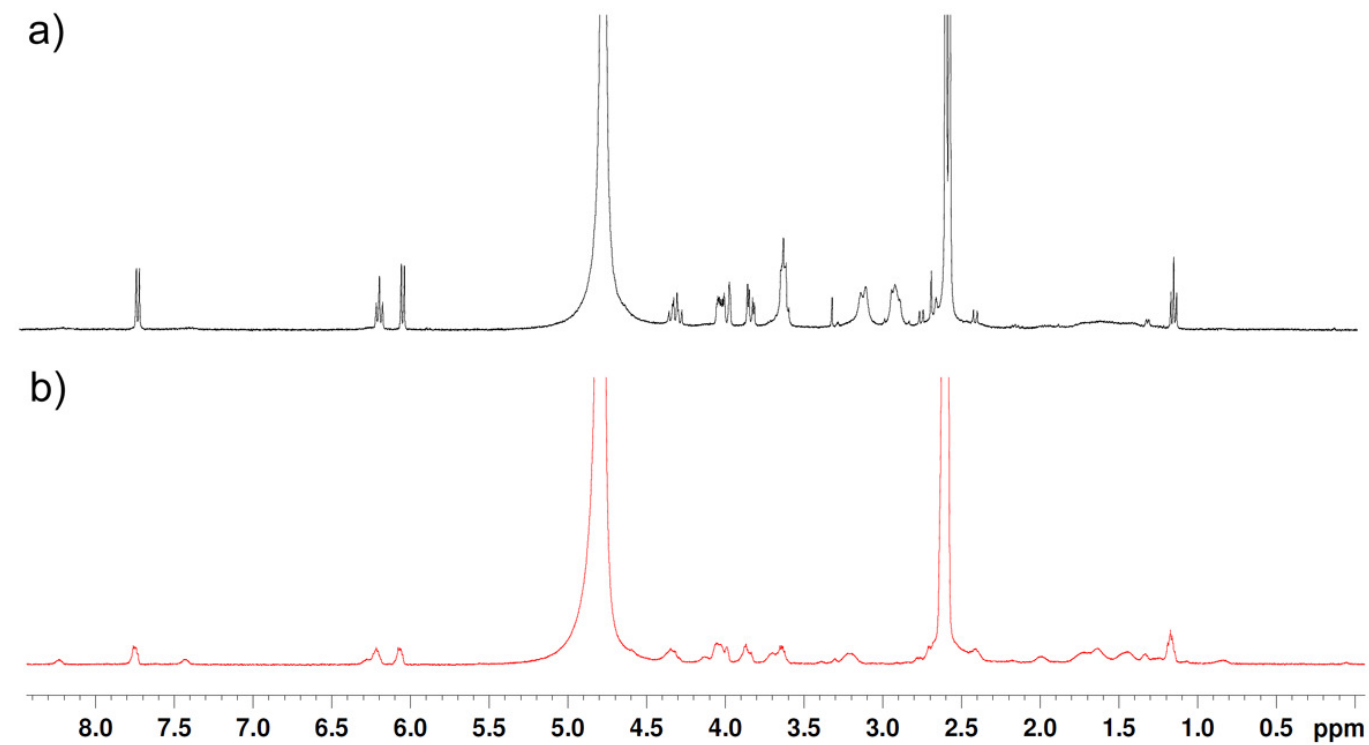

Figure 2S. ${ }^{1} \mathrm{H}$ NMR spectra of a $5 \mathrm{mM}$ aqueous solution of $\mathbf{1}$ (a) in $\mathrm{D}_{2} \mathrm{O}$, and (b) after cross-linking and dialysis. 


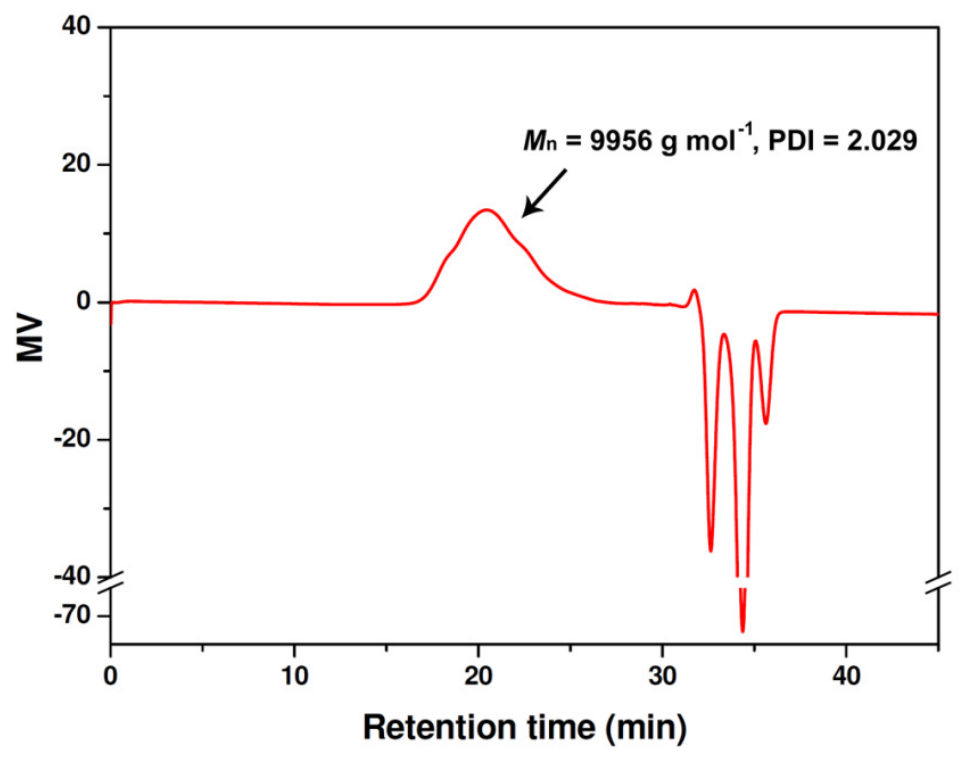

Figure 3S. GPC curve of the core-cross-linked small micelles formed by amphiphile $\mathbf{1}$.
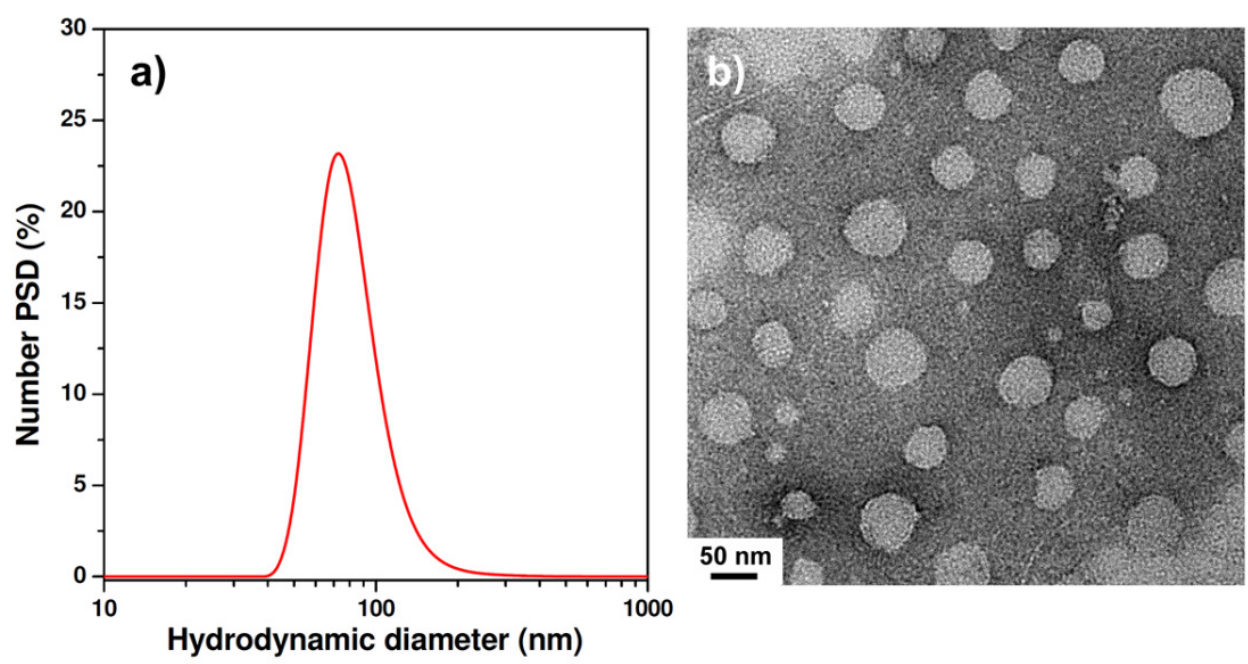

Figure 4S. Characterization of targeted cross-linked small-molecule micelles formed by amphiphile $\mathbf{1}$ and 2 in aqueous solution. (a) Distribution of the hydrodynamic diameter determined by DLS. (b) TEM morphology stained with an aqueous solution of $2 \%$ phosphotungstic acid. $[\mathbf{1}]=5.0 \times 10^{-4} \mathrm{M},[2]=5.0$ $\times 10^{-5} \mathrm{M}$. 


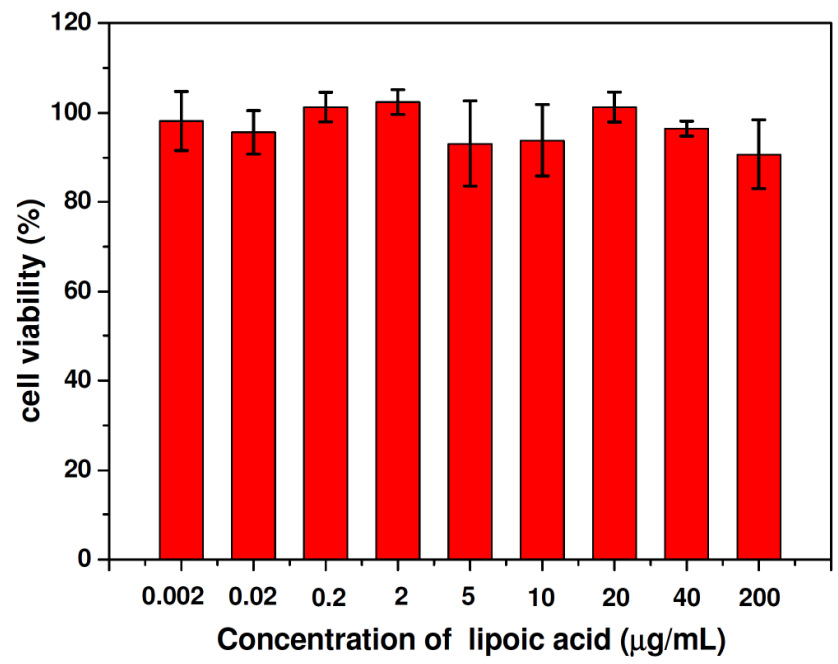

Figure 5S Cytotoxicity of cross-linked micelles formed by lipoic acid against A549 cells for $72 \mathrm{~h}$ incubation. 
${ }^{1} \mathrm{H},{ }^{13} \mathrm{C}$ NMR, and MS Spectra of Compounds 1 and 2.

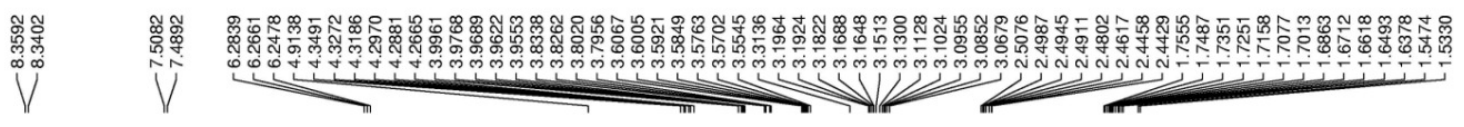

LCY01-44, $\mathrm{CD}_{3} \mathrm{OD}$

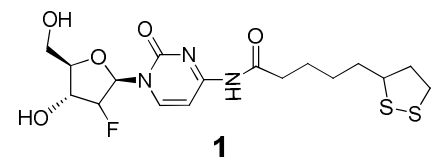
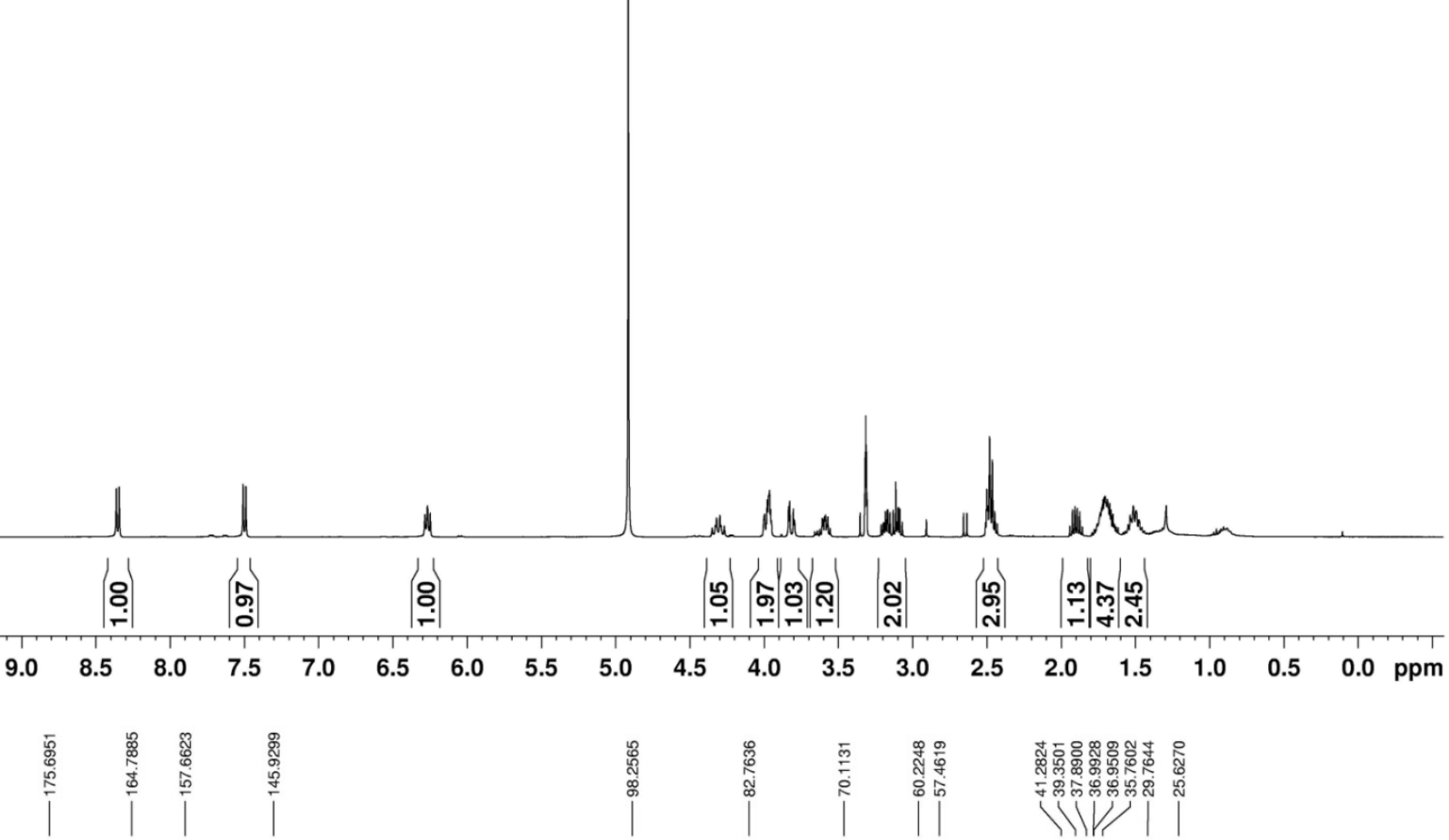

LCY01-44, $\mathrm{CD}_{3} \mathrm{OD}$
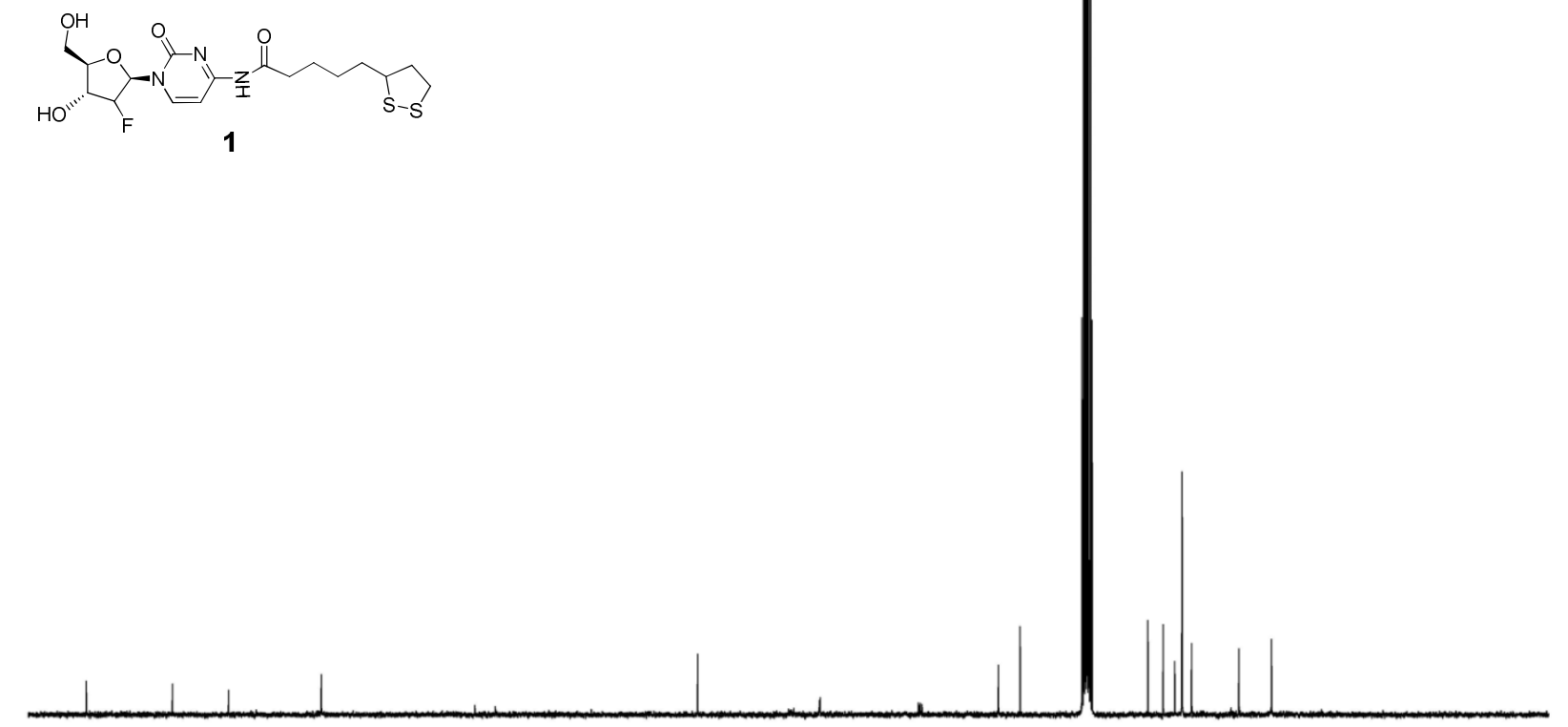

$\begin{array}{llllllllllllllllllll}180 & 170 & 160 & 150 & 140 & 130 & 120 & 110 & 100 & 90 & 80 & 70 & 60 & 50 & 40 & 30 & 20 & 10 & 0 & \mathrm{ppm}\end{array}$ 

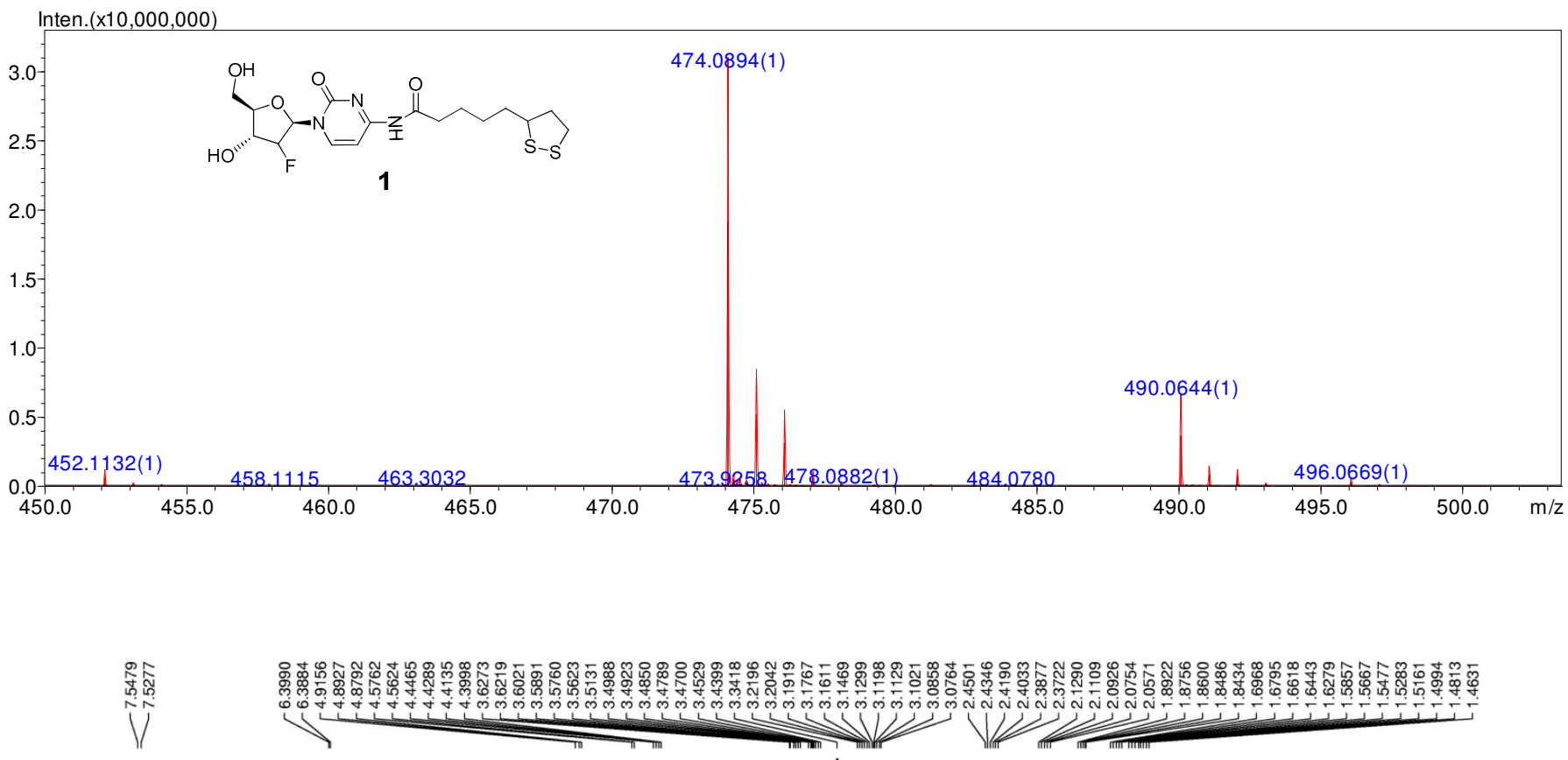

LCY02-94, DMSO<smiles>O=C(NCCO)NC(O)CCCCC1CCSS1</smiles>

2

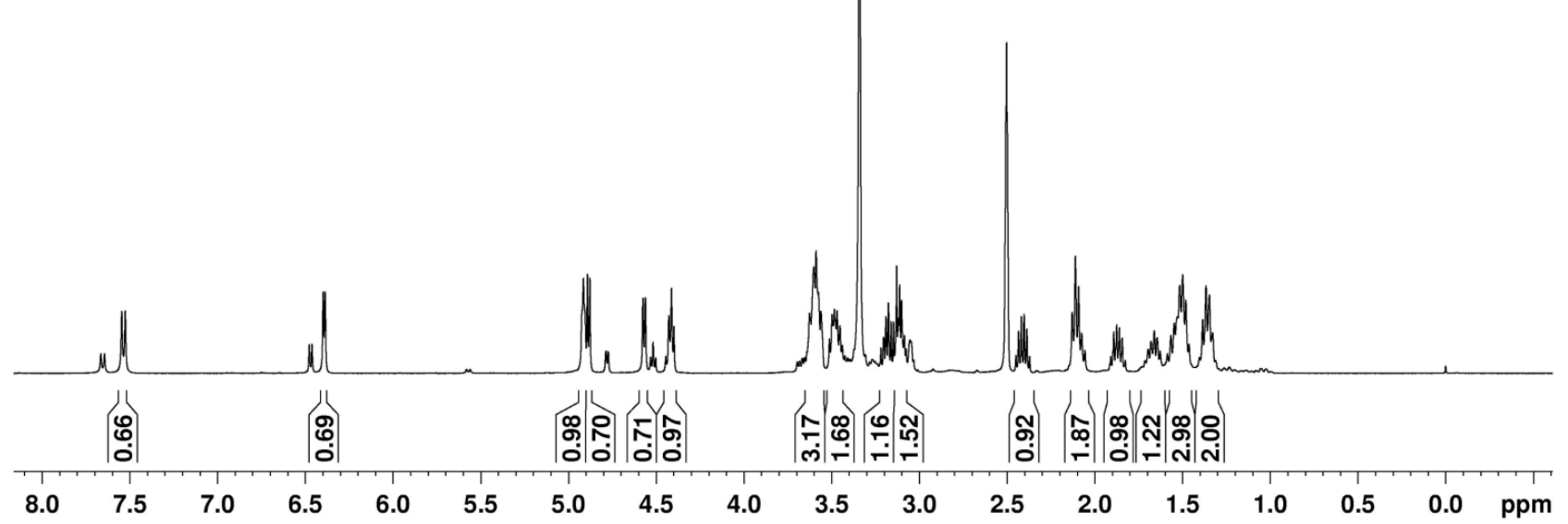



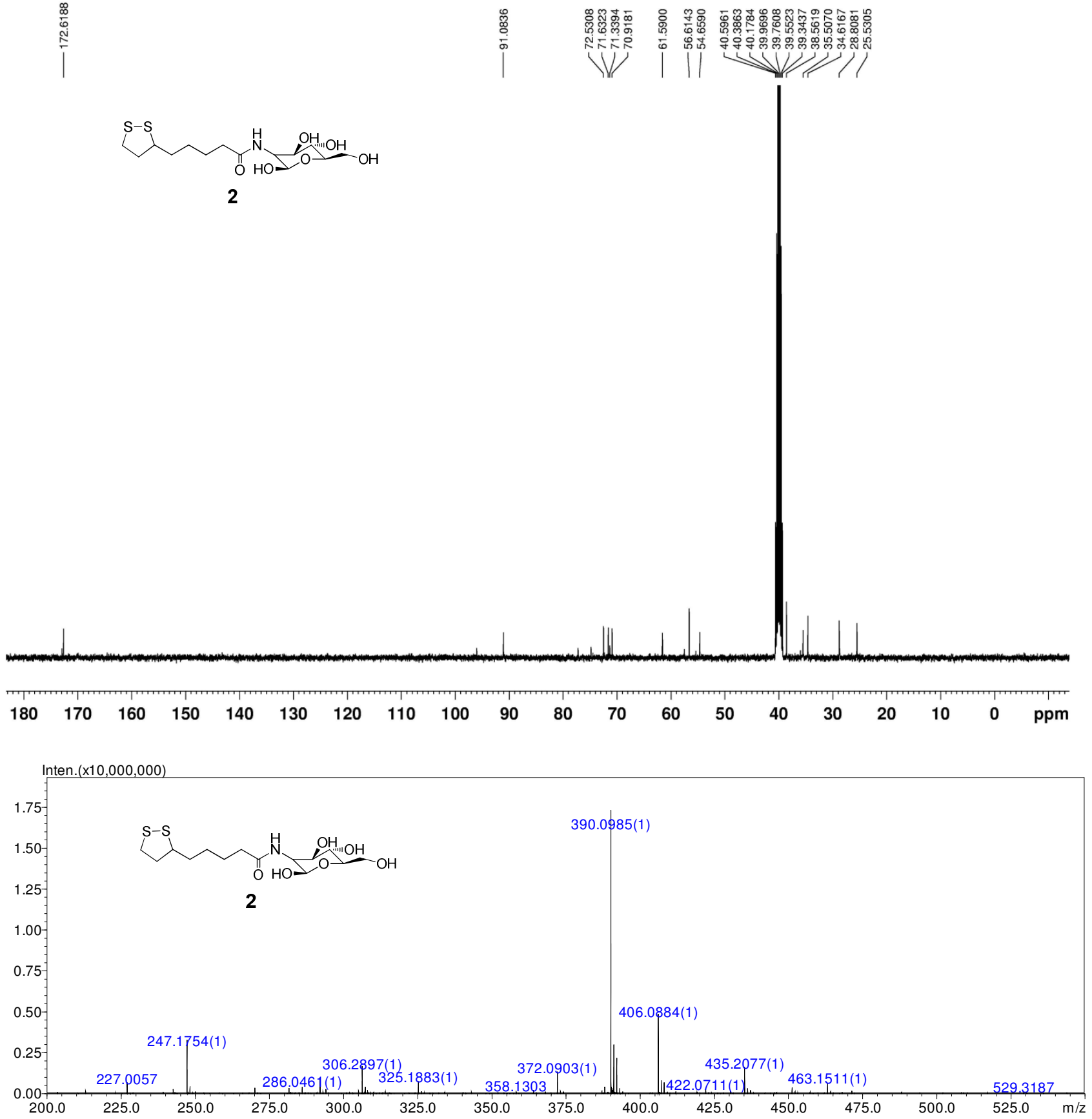